\title{
SOMATOTYPE PROFILES OF SLOVAK AND SAUDI ARABIAN MALE SOCCER PLAYERS ACCORDING TO PLAYING POSITIONS
}

\author{
Adriana Kaplánová ${ }^{1}$, Peter Šagát ${ }^{2}$, Pablo Prieto Gonzalez ${ }^{2}$, Peter Bartík ${ }^{3}$, and Martin Zvonař ${ }^{4}$ \\ ${ }^{1}$ Faculty of Physical Education and Sport, Comenius University in Bratislava, Slovakia \\ ${ }^{2}$ Department Physical Education, Health and Recreation, \\ Prince Sultan University in Riyadh, Kingdom of Saudi Arabia \\ ${ }^{3}$ Faculty of Health, Catholic University in Ružomberok, Slovakia \\ ${ }^{4}$ Faculty of Sports Studies, Masaryk University in Brno, Czech Republic
}

Original scientific paper

DOI 10.26582/k.52.1.17

\begin{abstract}
:
Somatotype of the human body is influenced by many factors. In addition to genetic, there are also environmental factors and cultural differences. The aim of this study was to compare the morphological configuration of men's body of Slovak and Saudi Arabian soccer players and find out the differences between soccer players in different playing positions. The study sample consisted of 50 Slovak soccer players aged 19-26 years (21.28 \pm 1.46$)$, including 18 defenders, 13 forwards, six goalkeepers, and 13 midfielders, and 50 Saudi Arabian soccer players aged 18-25 years (20.12 \pm 1.77 ), including 16 defenders, 20 forwards, four goalkeepers, and 10 midfielders. The used Heath-Carter method categorizes people into 13 groups according to the predominant physical component. The results indicated that soccer players differed among themselves according to playing positions. Slovak defenders and forwards were balanced mesomorphs, Slovak goalkeepers were endomorphic mesomorphs and central type was the predominant in Slovak midfielders. Almost all Saudi Arabian soccer players were predominantly mesomorph-endomorphs, with the exception of the defenders who were endomorphic mesomorphs. On average, the predominant somatotype of Slovak soccer players was balanced mesomorph (2-8,4-1,2-4), and of Saudi Arabian soccer players mesomorph-endomorph (3-8,4$3,1-4)$. It seems that the somatotype of soccer players varies depending on the country as well as the playing position. Therefore, it is necessary to examine anthropometry also with regard to geographical and cultural differences. In addition, regular evaluation of soccer players' somatotype can help coaches implement exercise elements that would probably increase players' sports performance.
\end{abstract}

Key words: anthropometry, body height, body weight, BMI, playing positions

\section{Introduction}

Soccer is one of the most popular sports watched with great interest in all countries of the world (Orhan, Sagir, \& Zorba, 2013). In important moments of the match, the most common movement of a soccer player is to run with high intensity. Experts report that up to $90 \%$ of all highintensity runs are done within five seconds and moreover $45 \%$ of soccer goals are scored after a high-intensity intensity running (Andrzejewski, Chmura, Pluta, \& Kasprzak, 2012; Faude, Koch, \& Meyer, 2012). Wong, Chamari, Dellal, and Wisloff (2009) found that most high-intensity runs were done by forwards and midfielders. Therefore, in terms of somatotypology, it is effective to select forwards and midfielders with a lower body weight and lower body height, which can increase their speed in important moments of the match. Research results of Wong et al. (2009) show that body height of soccer players positively correlates with the vertical jump performance. It seems that it is effective to select defenders with a higher body height who can more easily defend the balls directed from the opposing forwards. Wong et al. (2008) also found that goalkeepers have a higher body mass index (BMI) compared to defenders, midfielders, and forwards. Given the nature of this finding, it seems effective to select goalkeepers among soccer players with a higher body weight and body height who can more easily defend and catch the ball (Gil, Gil, Ruiz, Irazusta, \& Irazusta, 2007; Wong, et al., 2008, 2009). Although body shape and size are 
not the only variables necessary to determine the success of athletes, they may represent important prerequisites for certain sports (Gualdi-Russo \& Zaccagni, 2001).

Changes in size and proportion of the human body are largely influenced by genetic factors (Peeters, et al., 2007; Pereira, et al., 2016; Saranga, et al., 2008). However, heritability is not the only factor that affects variability in the bodily constitution of humans (Fragoso, Fortes, Viera, \& Castro, 2003; Lee \& Lin, 2007; Makgae, Monyeki, Brits, Kemper, \& Mashita, 2009; Veldre, 2004). Saranga et al. (2008) report that environmental factors have a significant impact on the human body's size and proportionality as well as the number of calories taken in via food and drinks, and the level of physical activity of people. The frequency, intensity and method of training load application affects the percentage of fat mass and contribute to the change in proportionality of the human body (Malina, Bouchard, \& Or, 2004). By analysing the physical composition of athletes of various specializations, the impact of sports training and physical exercise on the human body can be assessed as well as the adequacy of the implemented exercise elements (Gil, et al., 2007).

Biotypology using the Heath-Carter anthropometric somatotype is one of the most widely used methods for the selection of gifted and talented people for sports (Sterkowicz-Przybycien \& GualdiRusso, 2018). Analysis of morphological parameters of athletes helps to define optimal somatic prerequisites for quality performance in various sports disciplines (Kokaisl, 2007). Athletes who have achieved excellent results in their sports specialization represent a specific model to other athletes, respectively a somatic and physical pattern that has predisposed them to successful sports performances (Ziv, \& Lidor, 2009). Therefore, there are currently a number of studies that have investigated the somatotypology of athletes in a variety of sports such as judo (Noh, Kim, \& Kim, 2014), gymnastics (Purenovic-Ivanovic \& Popovic, 2014), canoeing (Ackland, Ong, Kerr, \& Ridge, 2003), ballet (Liiv, et al., 2013), wrestling (Ramirez-Velez et al., 2014), basketball (Ayan \& Erol, 2016; Rupčić, Matković, Knjaz, Baščevan, \& Rodić, 2011), mountain climbing (Barbieri, Zaccagni, Cogo, \& GualdiRusso, 2012), soccer (Reilly, Bangsbo, \& Franks, 2000), or volleyball (Carvajal, et al., 2012).

The analysis of somatotypes of athletes from different countries of the world has revealed some differences in their anthropometric characteristics. For example, Turkish soccer players were classified as balanced mesomorphs (2-4,4-8,2-3), featuring a predominance of a muscle-skeletal component and a balance of fat and linearity components (Hazir, 2010). In case of Zimbabwean soccer players, the mean somatotype rating reached values of
1-4,4-4,3-2, indicating ectomorphic-mesomorph (Makaza, Amusa, Goon, Tapera, \& Gundani, 2012). Croatian amateur soccer players were classified as endomorph-mesomorph. In comparison to elite soccer players, Croatian amateur soccer players were more endomorphic and less mesomorphic. It is very likely that such body build diminishes the quality of their performance in competitions (Erceg, Grgantov, \& Milić, 2013). There is currently a lack of studies to show differences in the somatotypology of soccer players of different countries, which would be examined at the same time and using the same tools. The aim of this study was to compare the morphological configuration of men's body of Slovak and Saudi Arabian soccer players and find out the differences between soccer players depending on playing positions. In the first hypothesis, we assumed that we would find significant differences in the anthropometric characteristics between the Slovak and Saudi soccer players. In the second hypothesis, we assumed that we would verify the significant differences between the Slovak and Saudi Arabian soccer players according to their playing positions.

\section{Methods}

\section{Participants}

The study sample consisted of 50 Slovak soccer players aged from 19 to 26 years $(21.28 \pm 1.46)$, composed of 18 defenders, 13 forwards, six goalkeepers and 13 midfielders, and 50 Saudi Arabian soccer players aged from 18 to 25 years $(20.12 \pm 1.77)$, composed of 16 defenders, 20 forwards, four goalkeepers and 10 midfielders. The Slovak soccer players had sports experience of $12.68 \pm 2.63$ years and Saudi Arabian soccer players of $10.76 \pm 1.87$ years. The participating soccer players were of a similar age, of a similar sports experience, and of a similar level of performance (university league), thus ensuring that we created a research sample suitable for international comparison using the same methods at the same time.

\section{Procedures}

For determining somatotypes of soccer players, we used the Heath-Carter method (Carter, 2002). The Heath-Carter method is one of the commonly used methods for somatotype determination that originated from the development of the classical Sheldon's photoscopic scheme of the assessment of body physique. The Heath-Carter somatotype represents three components: ectomorphy, mesomorphy and endomorphy. For the purpose of this study, we selected the Heath-Carter method because it allows categorizing soccer players into 13 groups according to the predominant physical component (Carter, 2002). 
In order to ensure objective comparability of the results, we tried to create identical data collection conditions with the use of uniform research tools. Body height of soccer players was measured by an anthropometer of GPM, with an accuracy of 0.1 centimetre. The soccer players stood upright with their backs leaning against the wall. Before the measurement, we checked that the soccer players were looking straight ahead and their heads were located in the Frankfort's horizontal plane. We measured the height from the ground to the vertex point. Body weight of soccer players was measured by a digital weight scale, with an accuracy of 0.1 kilogram, placed on a hard surface. Soccer players were weighed without shoes wearing minimal clothes (Kalinková \& Kalinka, 2008). We used the body height and body weight values of soccer players to calculate the ectomorphic component. The ectomorphy represents relative linearity of physique, which is the value of body height divided by cube root of body weight (height:weight ratio; HWR). According to the values of HWR parameter, we used one of the following equations: if HWR was greater than or equal to 40.75 , then ectomorphy $=0.732 \mathrm{HWR}-28.58$. If HWR was less than 40.75 but greater than 38.25 , then ectomorphy $=0.463$ HWR-17.63. If HWR was equal to or less than 38.25 , then ectomorphy $=0.1$ (Carter, 2002).

Mesomorphy represents a measure of musculoskeletal development. The value of the mesomorphic component of soccer players was calculated according to the following equation:

Mesomorphy $=0.858 \mathrm{x}$ humerus breadth +0.601 $\mathrm{x}$ femur breadth $+0.188 \mathrm{x}$ corrected arm girth + $0.161 \times$ corrected calf girth - body height $0.131+$ 4.5 (Carter, 2002).

Humerus breadth, as well as femur breadth, were measured by a sliding caliper model 105, with an accuracy of $0.1 \mathrm{~mm}$. Before measuring of humerus and femur breadth, we checked that the forearm and humerus as well as the lower leg and femur formed an angle of $90^{\circ}$. Arm girth as well as calf girth were measured by a sewing tape measure. Arm girth was measured at the site of the largest arc. Calf girth was measured at the site of the largest arch of the trigeminal calf muscle (Kalinková \& Kalinka, 2008). The girths were corrected by the subtraction of relevant skinfolds.

Endomorphy represents relative body fatness of the human body. The endomorphic component was calculated according to the following equation:

Endomorphy $=-0.7182+0.1451(\mathrm{X})-0.00068(\mathrm{X} 2)+$ $0.0000014(\mathrm{X} 3)$,

where $X$ was the sum of the values of triceps, subscapular and suprailiac skinfolds multiplied by $170.18 /$ body height. The values of the individual components of the somatotype were evaluated on the following scale: $2.5 \leq$ low values, $<3-5>$ medium values, $5.5 \geq$ high values (Carter, 2002). All values of skinfolds were measured by a modified caliper Best II K-501. The triceps skinfold was measured in a standing position, on the right side of the body halfway between the acromion and the olecranon. The subscapular skinfold was measured below the lower angle of scapula on the right side of the body in the direction obliquely downwards and laterally. The suprailiac skinfold was measured three centimetres from the lumbar bone in a slightly causal direction. The calf skinfold was measured on the medial side exactly at the level of the maximum calf breadth at the point of the largest arch of the trigeminal calf muscle (Kalinková \& Kalinka, 2008). This study was approved by the Research Ethics Committee (approval No. PSU IRB-201802-001). All participants were informed about the aims, methods of data collection and their use for research purposes. In addition, all participants gave their written informed consent in accordance with the Declaration of Helsinki.

\section{Statistical analysis}

The study is of a comparative research design that compares anthropometric characteristics of Slovak and Saudi Arabian soccer players. The SPSS statistical program (Version 23 for Windows, IBM, Armonk, NY, USA) was used to process and evaluate the obtained data. The Kolmogorov-Smirnov and Shapiro-Wilk tests of normality were applied to examine the data distribution. Due to the nonparametric distribution of the data, the Mann-Whitney U-test was used to compare the observed anthropometric parameters between the Slovak and Saudi Arabian soccer players. The level of significance was set at $p<05$. Effect size was expressed by point biserial correlation $r$, whereby a small effect was in an interval $.10 \leq \mathrm{r}<.30$, a medium effect was in an interval $.30 \leq r<.50$, and a large effect was $r \geq .50$. Somatotype distributions of Slovak and Saudi Arabian soccer players were shown by somatocharts (Carter, 2002).

\section{Results}

Table 1 presents mean values (M) and standard deviations (SD) of anthropometric parameters of Slovak and Saudi Arabian soccer players, as well as significant differences between the groups (p) and effect size (r). As can be seen, some anthropometric parameters differed between the Slovak and Saudi Arabian soccer players. Statistically significant differences were observed mainly in the thickness of skinfolds, namely in triceps skinfold $(\mathrm{p}<.01 ; \mathrm{r}=.39)$, subscapular skinfold $(\mathrm{p}<.01 ; \mathrm{r}=.31)$, suprailiac skinfold $(\mathrm{p}<.01 ; \mathrm{r}=.36)$, and calf skinfold $(\mathrm{p}<.01 ; \mathrm{r}=.46)$. Despite the fact that the average body weight of Slovak and Saudi Arabian soccer 
Table 1. Differences in anthropometric characteristics between the Slovak and Saudi Arabian soccer players

\begin{tabular}{|c|c|c|c|c|}
\hline Anthropometric parameters & $\begin{array}{l}\text { Slovak soccer players } \\
\qquad \begin{array}{c}(n=50) \\
M \pm S D\end{array}\end{array}$ & $\begin{array}{l}\text { Saudi Arabian soccer players } \\
\qquad \begin{array}{l}(n=50) \\
M \pm S D\end{array}\end{array}$ & $\mathbf{p}$ & $\mathbf{r}$ \\
\hline Body height $(\mathrm{cm})$ & $180.20 \pm 6.55$ & $175.76 \pm 7.12$ & .001 & .32 \\
\hline Body weight (kg) & $76.94 \pm 8.31$ & $78.84 \pm 13.17$ & .945 & .01 \\
\hline Triceps skinfold (cm) & $0.84 \pm 0.19$ & $1.11 \pm 0.42$ & .000 & .39 \\
\hline Subscapular skinfold $(\mathrm{cm})$ & $0.88 \pm 0.23$ & $1.10 \pm 0.40$ & .002 & .31 \\
\hline Suprailiac skinfold (cm) & $1.11 \pm 0.43$ & $1.49 \pm 0.57$ & .000 & .36 \\
\hline Calf skinfold (cm) & $0.85 \pm 0.24$ & $1.10 \pm 0.25$ & .000 & .46 \\
\hline Humerus breadth $(\mathrm{cm})$ & $6.23 \pm 0.45$ & $6.30 \pm 0.45$ & .509 & .07 \\
\hline Femur breadth $(\mathrm{cm})$ & $8.89 \pm 0.88$ & $9.03 \pm 1.10$ & .989 & .01 \\
\hline Corrected calf girth (cm) & $38.18 \pm 2.24$ & $37.74 \pm 2.17$ & .403 & .08 \\
\hline Corrected arm girth $(\mathrm{cm})$ & $35.26 \pm 2.30$ & $33.72 \pm 3.61$ & .010 & .26 \\
\hline
\end{tabular}

Note. $\mathrm{M}$ - mean value, $S D$ - standard deviation, $p$ - significance $(p<.01), r$ - effect size (small effect $.10 \leq r<.30$, medium effect .30 $\leq r<.50$, large effect $r \geq .50$ ), $\mathrm{cm}$ - centimetre, $\mathrm{kg}$ - kilogram.

Table 2. Differences in somatotypes of soccer players by playing positions

\begin{tabular}{llccc}
\hline Playing positions & Country & $\mathrm{n}$ & Somatotype & Somatochart \\
\hline Defenders & Slovakia & 18 & $2-7,4-4,2-6$ & 1 \\
& Saudi Arabia & 16 & $3-9,4-7,1-8$ & 12 \\
Forwards & Slovakia & 13 & $2-7,4-2,2-5$ & 1 \\
& Saudi Arabia & 20 & $3-7,4-2,1-3$ & 11 \\
Goalkeepers & Slovakia & 6 & $3-6,4-8,2-1$ & 12 \\
& Saudi Arabia & 4 & $5-3,5-7,0-9$ & 11 \\
Midfielders & Slovakia & 13 & $3-7,3-3,2-6$ & 13 \\
& Saudi Arabia & 10 & $3-3,3-5,1-4$ & 11 \\
\hline
\end{tabular}

Note. 1 - balanced mesomorph, 11 - mesomorph-endomorph, 12 - endomorphic mesomorph, 13 - central type.

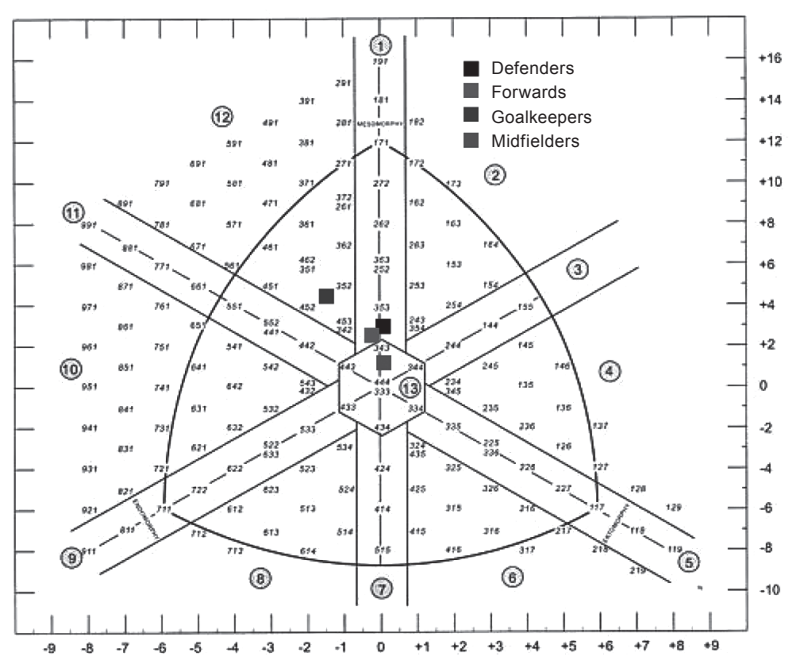

Figure 1. Dominant somatotypes of Slovak soccer players by positions.

players was not significantly different ( $\mathrm{p}>.05 ; \mathrm{r}=.01$ ), the results of our study show that the Slovak soccer players were on average four centimetres taller than the soccer players from Saudi Arabia $(\mathrm{p}<.01$; $\mathrm{r}=.32$ ). Statistically significant differences were also found between the monitored soccer groups in the

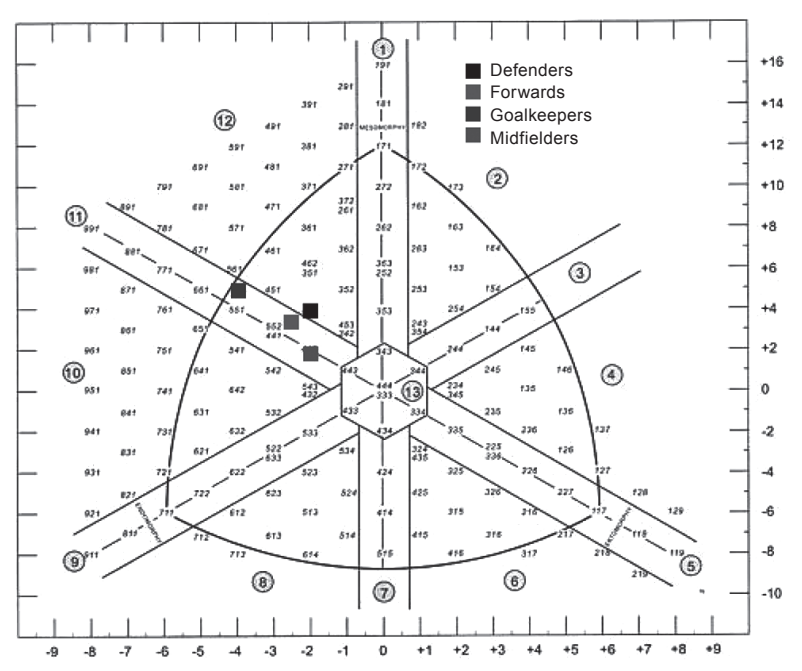

Figure 2. Dominant somatotypes of Saudi Arabian soccer players by positions.

corrected arm girth $(\mathrm{p}<.01 ; \mathrm{r}=.26)$. The difference in the humerus $(\mathrm{p}>.05 ; \mathrm{r}=.07)$ and femur breadth $(\mathrm{p}>.05 ; \mathrm{r}=.01)$ proved to be statistically insignificant, as well as the corrected calf girth $(\mathrm{p}>.05 ; \mathrm{r}=.08)$.

The Slovak and Saudi Arabian soccer players were categorized into relevant categories by the 


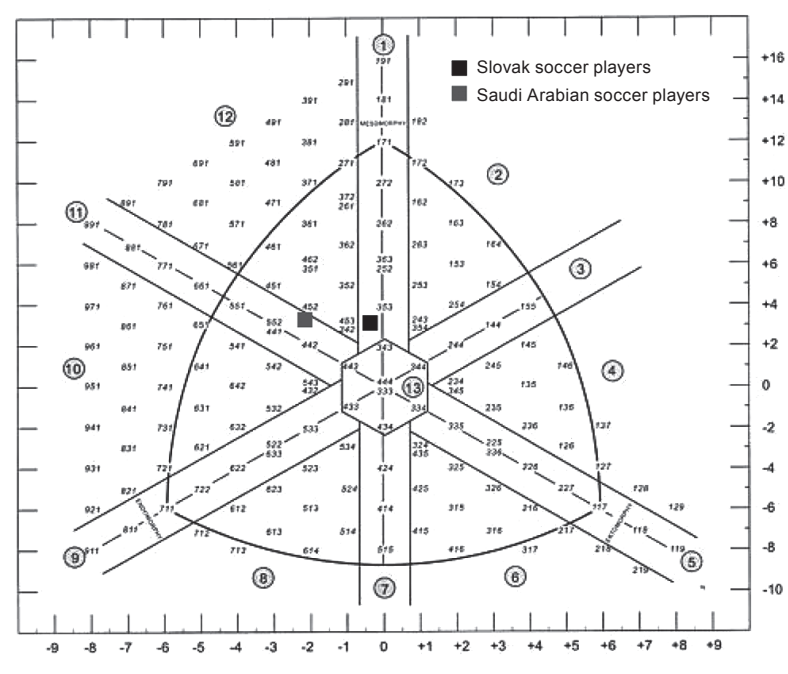

Figure 3. Dominant somatotypes of Slovak and Saudi Arabian soccer players.

Heath-Carter method: (1) balanced mesomorph, (2) ectomorphic mesomorph, (3) mesomorph-ectomorph, (4) mesomorphic ectomorph, (5) balanced ectomorph, (6) endomorphic ectomorph, (7) endomorph-ectomorph, (8) ectomorphic endomorph, (9) balanced endomorph, (10) mesomorphic endomorph, (11) mesomorph-endomorph, (12) endomorphic mesomorph, (13) central type (Carter, 2002). As we can see in Table 2, the balanced mesomorph type was predominant for the Slovak forwards (2-7,4-2,2-5) and defenders (2-7,4-4,2-6); the central type was predominant for the Slovak midfielders (3-7,3-3,2-6). For the Slovak goalkeepers, endomorphic mesomorph was typical (3-6,4-8,2-1). Graphic results of the Slovak soccer players are presented in Figure 1. Figure 2 presents results of the Saudi Arabian soccer players' somatochart. As we can see, the predominant somatotype for almost all the Saudi Arabian soccer players was mesomorphendomorph (forwards 3-7,4-2,1-3; midfielders 3-3,35,1-4; goalkeepers 5-3,5-7,0-9), with the exception of the defenders who were predominantly endomorphic mesomorphs (3-9,4-7,1-8). On average, the predominant somatotype for the Slovak soccer players was balanced mesomorph (2-8,4-1,2-4), whereas for the Saudi Arabian soccer players it was mesomorph-endomorph (3-8,4-3,1-4), which is presented in Figure 3.

\section{Discussion and conclusion}

Until now, it has not been possible to unequivocally prove that somatotypology of soccer players is uniform in all countries of the world. Although there are research studies that have confirmed balanced mesomorph as the predominant somatotype in many countries (Fidelix, et al., 2014; Orhan, Zagir, \& Zorba, 201), there are also research studies that have reported some differences in the constitution of the human body according to countries or playing positions (Hazir, 2010; Makaza, et al., 2012).
Therefore, the aim of this study was to compare the morphological configuration of men's body of the Slovak and Saudi Arabian soccer players and find out the differences between soccer players playing different positions.

We found that in both the Saudi Arabian and the Slovak soccer players a mesomorphic component predominated, the component which had been proven to be most genetically conditioned in terms of heritage (Peeters, et al., 2007). The differences were revealed in relation to the proportion of the endomorphic component, which was higher in the Saudi Arabian soccer players. Peeters et al. (2007) report that the endomorphic component is least affected by heritability, hence environmental factors, such as frequency and load of sports training, and the nutritional value of food consumed have a significant impact on it (Saranga, et al., 2008). Although the Slovak soccer players had a profile of balanced mesomorphs (2-8,4-1,2-4) and the Saudi Arabian soccer players had a profile of mesomorph-endomorphs (3-8,4-3,1-4), the differences between them were caused mainly by the proportion of endomorphic component, which can be changed by proper training programmes and consumption of nutritionally valuable foods (Saranga, et al., 2008).

The Slovak soccer players were on average four centimetres taller compared to the Saudi Arabian peers, but their average body weight was almost equal. The value of BMI revealed that the Slovak soccer players belonged to a normal-weight group $(23.69 \pm 2.05)$ and the Saudi Arabian soccer players were at the edge between the normal weight and overweight (25.42 \pm 3.06$)$, which was also evidenced by the recorded higher proportion of endomorphic component. Our findings are consistent with the findings of the World Health Organization findings (WHO, 2018), which revealed a higher prevalence of overweight in the Saudi Arabian population. The cause of a higher body weight of the Saudi Arabian population may be the consumption of nutritionally poorer but caloric meals and sweetened beverages (Al-Otaibi, 2017), or the ever-growing sedentary lifestyle (Al-Hazzaa, Abahussain, Al-Sobayel, Qahwaji, \& Musaiger, 2011; Alsubaie \& Omer, 2015). The warmer climatic conditions in Arab countries can lead to lower physical activity and thus to a higher proportion of fat, which was also reflected in the results of our research, where the Saudi Arabian soccer players differed from the Slovak counterparts in thickness of skinfolds. A higher training frequency and a greater training load of the Slovak soccer players were probably reflected in the bicep's circumference, which showed significant differences compared to the Saudi Arabia soccer players.

Differences were found not only between the soccer players of two countries - Slovakia and Saudi Arabia, but also between playing positions 
which was also consistent with the findings of other authors (Erceg, Grgantov, \& Milić, 2013; Gil, et al., 2007; Hazir, 2010; Orhan, et al., 2013). The Slovak defenders and forwards were predominantly balanced mesomorphs, which type presents relative musculo-skeletal maturity of the human body. In soccer, a defender is a player whose primary roles are to stop attacks during the game and prevent the opposing team from scoring a goal, whereas a forward is a player who tries to overcome and outplay the opponent's defense and score a goal. Both need to quickly change direction, run up or jump high to either block the ball (defender) or direct a header on goal (forward), therefore for both the balanced mesomorph type seems ideal (Hazir 2010; Orhan, et al., 2013). The central type was dominant for the Slovak midfielders. The midfielders' play is characterized by moving over long distances, and for this reason they should be best physically apt and prepared. Therefore, in terms of somatotypology, it is effective to select midfielders with a lower body weight and lower body height, which can increase their speed in important moments of a match (Wong, et al., 2009). In the Slovak goalkeepers as well as in the Saudi Arabian defenders the endomorphic mesomorph type predominated (Gil, et al., 2007). Wong et al. (2008) recommend selecting goalkeepers and defenders with a higher body weight and body height who can more easily defend and catch the ball. The endomorphic mesomorph type, characterized by a higher body fatness, would seem effective for goalkeepers and defenders which is also consistent with the findings by Gilt et al. (2007) and Hazir (2010). For the Saudi Arabian forwards, midfielders and goalkeepers, the mesomorph-endomorph type was typical, which is characterized by the same or similar proportions of mesomorphic as well as endomorphic component. Erceg, Grgantov, and Milić (2013) also found that the Croatian elite soccer players, in comparison to the Croatian amateur soccer players, were more endomorphic and less mesomorphic. There are some assumptions that by implementing appropriate training programmes we can improve performance of soccer players in these playing positions. The results of our research also encourage us to think about the diet of young people and the current increasing trend of a sedentary lifestyle, which is reflected in non-compliance with the standards set by the World Health Organization (WHO, 2018). For this reason, we would also like to appeal for the expansion of research on the nutritional value of meals of soccer players and on the subsequent impact of an unbalanced diet on the health of young people. We believe that the results of our research will be stimulating to experts in the field, and will provide a basis for a deeper examination of the issue.

The results of our study have shown that the somatotype of soccer players varies depending on the country as well as the playing positions. Therefore, it is necessary to examine anthropometry also with regard to geographical and cultural differences. The results of our research also show that it is important to regularly control body fat of soccer players and undertake somatotype assessment which can demonstrate a higher proportion of endomorphic components and indicate the need to implement specific exercise elements. A detailed analysis of players' components pointed to the need for proper lifestyle or consumption of meals with appropriate nutritional value, as well as the need to implement training elements developing soccer skills of players. It seems that implementation of appropriate exercise elements that influence the proportion of the human body can contribute to better sports performance.

\section{References}

Ackland, T.R., Ong, K.B., Kerr, D.A., \& Ridge, B. (2003). Morphological characteristics of Olympic sprint canoe and kayak paddlers. Journal of Science and Medicine in Sport, 6(3), 285-294. doi: 10.1016/s1440-2440(03)80022-1

Al-Hazzaa, H.M., Abahussain, N.A., AL-Sobayel, H.I., Qahwaji, D.M., \& Musaiger, A.O. (2011). Physical activity, sedentary behaviors and dietary habits among Saudi adolescents relative to age, gender and region. International Journal of Behavioral Nutrition and Physical Activity, 8, 1-14. doi: 10.1186/1479-5868-8-140

Al-Otaibi, H.H. (2017). Sugar sweetened beverages consumption behavior and knowledge among university students in Saudi Arabia. Journal of Economics, Business and Management, 5(4), 173-176. doi: 10.18178/joebm.2017.5.4.507

Alsubaie, A.S., \& Omer, E.O. (2015). Physical activity behavior predictors, reasons and barriers among male adolescents in Riyadh, Saudi Arabia: Evidence for obesogenic environment. International Journal of Health Sciences, 9(4), 400-408. doi: 10.12816/0031229

Andrzejewski, M., Chmura, J., Pluta, B., \& Kasprzak, A. (2012). Analysis of sprinting activities of professional soccer players. Journal of Strength and Conditioning Research, 27(8), 2134- 2140. doi: 10.1519/JSC.0b013e318279423e

Ayan, V., \& Erol, E. (2016). The study of the somatotype structures and the performance characteristics of Turkey's U15 men's national basketball team players. Kastamonu Eğitim Dergisi, 24(4), 2089-2098. 
Barbieri, D., Zaccagni, L., Cogo, A., \& Gualdi-Russo, E. (2012). Body composition and somatotype of experienced mountain climbers. High Altitude Medicine and Biology, 13(1), 46-50. doi: 10.1089/ham.2011.1062

Carter, J.E.L. (2002). The Heath-Carter anthropometric somatotype-Instruction manual. San Diego: San Diego State University.

Carvajal, W., Betancourt, H., León, S., Deturnel, Y., Martínez, M., Echevarría, I., Castillo, M.E., \& Serviat, N. (2012). Kinanthropometric profile of Cuban women Olympic volleyball champions. MEDICC Review, 14(2), 16-22. doi: 10.1590/s1555-79602012000200006

Erceg, M., Grgantov, Z., \& Milić, M. (2013). Somatotype of Croatian amateur soccer players-Positional differences. Indian Journal of Applied Research, 3(11), 246-248. doi: 10.15373/2249555X/NOV2013/79

Faude, O., Koch, T., \& Meyer, T. (2012). Straight sprinting is the most frequent action in goal situations in professional football. Journal of Sports Sciences, 30(7), 625-631. doi: 10.1080/02640414.2012.665940

Fidelix, Y.L., Berria, J., Ferrari, E.P., Ortiz, J.G., Cetolin, T., \& Petroski, E.L. (2014). Somatotype of competitive youth soccer players from Brazil. Journal of Human Kinetics, 42, 259-266. doi: 10.2478/hukin-2014-0079

Fragoso, I., Fortes, M., Viera, F., \& Castro, L.C. (2003). Identifying maturational levels during adolescence: A methodological problem. In M. Marfell-Jones \& T. Reilly (Eds.), Kinanthropometry VIII (pp. 69-82). London: Routledge.

Gil, S.M., Gil, J., Ruiz, F., Irazusta, A., \& Irazusta, J. (2007). Physiological and anthropometric characteristics of young soccer players according to their playing position: Relevance for the selection process. Journal of Strength and Conditioning Research, 21(2), 438-445. doi: 10.1519/R-19995.1

Gualdi-Russo, E., \& Zaccagni, L. (2001). Somatotype, role and performance in elite volleyball players. Journal of Sports Medicine and Physical Fitness, 41(2), 256-262.

Hazir, T. (2010). Physical characteristics and somatotype of soccer players according to playing level and position. Journal of Human Kinetics, 26, 83-95. doi: 10.2478/v10078-010-0052-z

Kalinková, M., \& Kalinka, P. (2008). Somatotypológia, somatometria a somatopsychológia v športe. [Somatotypology, somatometry and somatopsychology in sport. In Slovak.] Bratislava: PEEM.

Kokaisl, P. (2007). Základy antropologie. [Introduction to anthropology. In Czech.]. Praha: Nostalgie.

Lee, A.J., \& Lin, W.H. (2007). The influence of gender and somatotype on single-leg upright standing postural stability in children. Journal of Applied Biomechanics, 23(3), 173-179. doi: 10.1123/jab.23.3.173

Liiv, H., Wyon, M., Jürimäe, T., Saar, M., Mäestu, J., \& Jürimäe, J. (2013). Anthropometry, somatotypes, and aerobic power in ballet, contemporary dance, and dancesport. Medical Problems of Performing Artists, 28(4), $207-211$.

Little, T., \& Williams, A.G. (2006). Effects of differential stretching protocols during warm-ups on high-speed motor capacities in professional soccer players. Journal of Strength and Conditioning Research, 20(1), 203-207. doi: 10.1519/R-16944.1

Makaza, D., Amusa, L.O., Goon, D.T., Tapera, E.M., \& Gundani, M.P. (2012). Body composition and somatotype profile of male Zimbabwean junior soccer players. Medicina dello Sport, 65(1), 63-74.

Makgae, P., Monyeki, K.D., Brits, S., Kemper, H.C.G., \& Mashita, J. (2009). Somatotype and blood pressure of rural South African children aged 6-13 years: Ellisras Longitudinal Growth and Health Study. Annals of Human Biology, 34(2), 240-251. doi: 10.1080/03014460601144219

Malina, R., Bouchard, C., \& Or, O.B. (2004). Growth, maturation, and physical activity. Champaign, IL: Human Kinetics.

Noh, J.W., Kim, J.H., \& Kim, J. (2014). Somatotype analysis of elite judo athletes compared with nonathletes for health science research. Toxicology and Environmental Health Sciences, 6(2), 99-105. doi: 10.1007/s13530-014-0193-x

Orhan, O., Sagir, M., \& Zorba E. (2013). Comparison of somatotype values of football players in two professional league football teams according to the positions. Collegium Antropologicum, 37(2), 401-405.

Peeters, M.W., Thomis, M.A., Loos, R.J.F., Derom, C.A., Fagard, R., Claessens, A.L., Vlietinck, R.F., \& Beunen, G.P. (2007). Heritability of somatotype components: A multivariate analysis. International Journal of Obesity, 31, 1295-1301. doi: 10.1038/sj.ijo.0803575

Pereira, S., Katzmarzyk, P.T., Gomes, T.N., Souza, M., Chaves, R.N., Santos, F.K.D., Santos, D., Hedeker, D., \& Maia, J.A.R. (2016). Multilevel modelling of somatotype components: The Portuguese sibling study on growth, fitness, lifestyle and health. Annals of Human Biology, 44(4), 316-324. doi: 10.1080/03014460.2016.1243727

Purenović-Ivanović, T., \& Popović, R. (2014). Somatotype of top-level Serbian rhythmic gymnasts. Journal of Human Kinetics, 40(1), 181-187. doi: 10.2478/hukin-2014-0020

Ramirez-Velez, R., Argothyd, R., Meneses-Echavez, J.F., Sanchez-Puccini, M.B., Lopez-Alban, C.A., \& Cohen, D.D. (2014). Anthropometric characteristics and physical performance of Colombian elite male wrestlers. Asian Journal of Sports Medicine, 5(4), e23810. doi: 10.5812/asjsm.23810

Reilly, T., Bangsbo, J., \& Franks, A. (2000). Anthropometric and physiological predispositions for elite soccer. Journal of Sports Sciences, 18(9), 669-683. doi: 10.1080/02640410050120050

Rupčić, T., Matković, B., Knjaz, D., Baščevan, S., \& Rodić, S. (2011). Differences in the anthropological profile of the basketball referees with regard to their chronological age. Sportlogia, 7(1), 27-33. doi: 10.5550/sgia.110701. en.027R 
Saranga, S.P., Prista, A., Nhantumbo, L., Beunen, G., Rocha, J., Williams-Blangero, S., \& Maia, J.A. (2008). Heritabilities of somatotype components in a population from rural Mozambique. American Journal of Human Biology, 20(6), 642-646. doi: 10.1002/ajhb.20733

Sterkowicz-Przybycien, K., \& Gualdi-Russo, E. (2018). Evaluation of somatotype in artistic gymnastics competitors: A meta-analytical approach. Journal of Sports Medicine and Physical Fitness, 59(3), 449-455. doi: 10.23736/ S0022-4707.18.08332-9

Veldre, G. (2004). Heath-Carter somatotype categories and their sexual maturation differences in 12-15 years old Estonian boys and girls. Papers on Anthropology, 13, 269-285.

Wong, P., Chamari, K., Dellal, A., \& Wisloff, U. (2009). Relationship between anthropometric and physiological characteristics in youth soccer players. Journal of Strength and Conditioning Research, 23(4), 1204-1210. doi: 10.1519/JSC.0b013e31819f1e52

Wong, P., Mujika, I., Castagna, C., Chamari, K., Lau, P.W.C., \& Wisloff, U. (2008). Characteristics of World Cup soccer players. Soccer Journal, 53(1), 57-62.

WHO - World Health Organization. (2018). Obesity and overweight. Retrieved October 15, 2018 from: http://www. who.int/news-room/fact-sheets/detail/obesity-and-overweight

Ziv, G., \& Lidor, R. (2009). Physical attributes, physiological characteristics, on-court performances and nutritional strategies of female and male basketball players. Sports Medicine, 39(7), 547-568. doi: 10.2165/00007256200939070-00003

Submitted: February 14, 2020

Accepted: May 13, 2020

Published Online First: June 2, 2020

Correspondence to:

Adriana Kaplánová, Ph.D.

Faculty of Physical Education and Sport,

Comenius University in Bratislava, Slovakia

Nábrežie armádneho generála L. Svobodu 42e98/9,

814 69, Bratislava, Slovakia

Phone: +421908615773

E-mail: adriana.kaplanova@gmail.com

\section{Acknowledgments}

We would like to thank all soccer players who took part in the study, the entire research team and the coaches who helped us. The study was supported by the research grant: VEGA No. 1/0523/19. Physical and sports education and its' quality and potential in health promotion from the perspective of pupils, teachers and parents 2019-2021. 